\title{
4
}

\section{GTP QUESTÃO AGRÁRIA, URBANA, AMBIENTAL E SERVIÇO SOCIAL}

\author{
GTP AGRARIAN, URBAN, ENVIRONMENTAL \\ QUESTION AND SOCIAL SERVICE
}

\section{Coordenação}

Profa. Dra. Cristina Simões Bezerra (UFJF)

Profa. Dra. Debora Nascimento (UFAM)

Profa. Dra. Tânia Maria Ramos de Godoi Diniz (UNIFESP/BS)

Profa. Dra. Tatiana Dahmer Pereira (UFF)

Submetido em 04/07/2014

Aceito em 16/07/2014

\section{APRESENTAÇÃO}

Este texto propõe-se a apresentar o trabalho desenvolvido por um conjunto de pesquisadores que, articulados ao GTP, se dedicam a estudar, aprofundar e compartilhar conteúdos sobre a temática Questão Agrária, Urbana, Ambiental, dialogando com a formação em Serviço Social.

Tem como objetivo mostrar o caminho percorrido pelo GTP e pontuar alguns desafios que se apresentam para sua continuidade, haja vista a dinâmica societária atual, em tempos de sociabilidade capitalista, produtora de desumanidade pela apropriação privada da riqueza socialmente produzida (IASI, 2006). São tempos nos quais "os direitos da propriedade privada e taxa de lucro se sobrepõem a todas as outras noções de direitos" (HARVEY, 2012, p. 73), o que tem exigido dos pesquisadores Assistentes Sociais análises críticas dos marcos dos princípios e diretrizes do projeto profissional ético-político.

Apresentamos como premissa o fato de que a compreensão sobre a dinâmica histórica de constituição das dimensões agrária, 


\section{temporalis}

urbana e ambiental decorre de intrínseca articulação, sendo essas dimensões constituintes da realidade e expressões, com especificidades, da desigualdade que funda essa sociabilidade e seu modo de produção.

Consideramos que essa integração possui como um dos alicerces centrais o modelo de desenvolvimento hegemônico do modo de produção capitalista, cuja apropriação - por parte daqueles que detêm a propriedade privada dos meios de produção - dos recursos naturais, do espaço socialmente produzido e da força de trabalho no campo e nas cidades orienta-se por racionalidade predatória, reificadora e voltada à acumulação.

É nesse sentido que o GTP vem construindo sua trajetória, afirmando que as dimensões urbana, agrária e ambiental somente se tornam compreensíveis se apreendidas nas determinações do modo de produção capitalista, com base em leitura dialética, materialista e histórica sobre a natureza (FOSTER, 2011), integradas, portanto, em uma perspectiva de totalidade. $O$ desafio maior consiste, justamente, em investir para desmistificar a separação originária dessa racionalidade, concretizada a partir do modo de produção vigente. A divisão social, técnica, territorial e internacional do trabalho, mecanismo de produção da fragmentação e do consequente antagonismo, e a hierarquização entre campo e cidade têm sido elementos desafiadores para aqueles compromissados com transformações estruturais dessa sociedade (MARX, 1985).

Com base nos acúmulos e momentos de integração das pesquisas, consideramos que uma das tarefas centrais do GTP no processo de produção de conhecimento consiste em contribuir para a formação de profissionais e fomentar um debate crítico sobre leitura que rompa com a noção de "esferas" ou "dimensões" da vida social (WOOD, 2010), permitindo a construção de intervenções profissionais política e teoricamente alicerçadas em instrumentos de compreensão da totalidade dos processos e o reconhecimento das lutas por direitos, contra o modelo de desenvolvimento, e dos sujeitos sociais organizados a partir de projetos societários. 
Assim, o GTP tem desenvolvido suas atividades subsidiado pela seguinte ementa:

\begin{abstract}
Aprofundar a construção de fundamentos teórico-metodológicos, em uma perspectiva de totalidade, para embasar a análise crítica das expressões da questão social no âmbito da questão agrária, urbana e ambiental, em sua materialidade na realidade brasileira, bem como sobre as estratégias de intervenção profissional nestes campos (ASSOCIAÇÃO..., 2012, p. 464).
\end{abstract}

Ressaltamos, ainda, com base na investigação de lamamoto (2009), que, embora as dimensões urbana, agrária e ambiental perpassem todas as linhas de pesquisa, mesmo não sendo seu objeto central de tematização, estudos centrados em "movimentos sociais, processos organizativos e movimentos sociais com recortes nas relações de poder, conflitos sociais e poder local, questão urbana e rural" (IAMAMOTO, 2008, p. 459) atingiam, segundo informações da CAPES para 2004, menos do que $10 \%$ do universo de pesquisas em curso naquele período para a pós-graduação. Acreditamos que há incremento nesse percentual, cabendo não apenas seu mapeamento e atualização das informações, como também a compreensão sobre como se qualifica hoje esse universo de investigação nas Unidades de Formação Acadêmicas (UFAs).

\title{
HISTÓRICO DA ORGANIZAÇÃO DO GTP
}

Em meados da década de 1980, o Serviço Social brasileiro, impulsionado pelos movimentos de lutas pela redemocratização da sociedade e do Estado brasileiro, via-se desafiado a buscar novas respostas críticas às demandas profissionais, baseadas em uma compreensão de totalidade dialética e histórica. Assim, diante das determinações sociopolíticas, da origem da profissão na divisão social do trabalho e dos condicionantes históricos do Serviço Social, significativas alterações ocorreram nos processos de formação profissional, a partir das dimensões teórico-metodológica, ético-política e técnico-operativa, abrangendo desde o ensino e a pesquisa até a produção de conhecimento (IAMAMOTO, 2009). 


\section{temporalis}

A tônica predominante da ação do Assistente Social está na intervenção na realidade, objetivada através de um processo privilegiado de apropriação do real. Conforme Netto (2009), ainda que não se extraiam diretamente indicativos para a ação profissional do conhecimento produzido, o trabalho profissional crítico e propositivo deve estar subsidiado por conhecimentos sólidos.

Portanto, é nesse contexto acadêmico, fomentado pelo debate da relação da pesquisa com o ensino e o exercício profissional, que se desenvolve a pesquisa no Serviço Social (ainda que inserida tardiamente na profissão), contribuindo para sua maioridade intelectual e num diálogo profícuo com as ciências sociais (NETTO, 2009).

Registra-se que a Associação Brasileira de Ensino e Pesquisa em Serviço Social (ABEPSS), nas suas várias gestões durante a década de 2000, impulsionada pela apreensão da formação profissional como um processo permanente que articula graduação e pós-graduação e pela garantia de sua qualidade, assume o papel de "qualificação de quadros e fornecer subsídios para a graduação, na forma de massa crítica, na produção acadêmica e científica socialmente relevante" (REVISTA TEMPORALIS, 2009, p. 156).

O estatuto aprovado na Assembleia de 2008 prevê a "necessidade de criação dos grupos temáticos (GTs) para pesquisas na área de Serviço Social” (REVISTA TEMPORALIS, 2009, p. 156). Em 2009, a partir de debates e reflexões realizados sobre um documento base, foi aprovada a constituição de Colóquios no ENPESS de 2010, origem da criação dos GTPs, em sete eixos temáticos relacionados com o Serviço Social, bem como momento no qual as ementas construídas pelos pesquisadores envolvidos nesse esforço coletivo foram discutidas.

Nesse processo, as temáticas agrária, urbana e ambiental se constituem em um GTP devido à possibilidade de articulação do Serviço Social com o debate profissional, assumindo os objetivos propostos na "construção de espaços privilegiados para a reflexão teórica e estímulo efetivo para a elaboração, produção e circulação de conhecimento" (REVISTA TEMPORALIS, p. 158). Para responder aos objetivos, o GTP, então sob a coordenação dos professores Maristela Dal Moro (UFRJ), Maria das Graças e 
Silva (UFPE) e Percy Coelho (UnB), buscou identificar grupos e núcleos de pesquisa, assim como articular redes e linhas de pesquisa, realizando um levantamento preliminar da produção na área, orientando-se pelos seguintes eixos temáticos:

Determinações estruturais e históricas da questão urbana, agrária e ambiental no Brasil: a luta de classes como mediação

1- Formas de apropriação, de uso e de ocupação do solo urbano e rural. Propriedade privada da terra, trabalho e modos de produção e reprodução capitalista. Apropriação privada dos recursos naturais. Impactos da reconfiguração das atividades econômicas no campo e na cidade sobre o mundo do trabalho;

2- Economia política do desenvolvimento. Modo de desenvolvimento capitalista. O papel do Estado e as particularidades brasileira e latino-americana: a concentração fundiária, a constituição das classes sociais, o patrimonialismo e o autoritarismo;

3- Mundialização do capital e manifestações contemporâneas da crise estrutural do capital na cidade e no campo, implicações no mundo do trabalho e na organização política dos trabalhadores: agronegócio, novas implantações industriais, monocultura, destrutividade ambiental e processos de urbanização a partir de uma análise macro da estrutura societária;

4- Particularidades e desigualdades do desenvolvimento regional. A Amazônia e outras regiões do país que sofrem um processo intensivo de expropriação pelo capital, e seu papel no desenvolvimento capitalista.

O papel do Estado e as políticas públicas no campo e na cidade

1- Políticas urbanas e o direito à cidade;

2- Dinâmicas socioeconômicas e formas de apropriação, planejamento, uso e gestão dos territórios;

3- Regulação pública do meio ambiente e o discurso da sustentabilidade;

4- Política agrária: trabalho, propriedade privada da terra, soberania alimentar, transgenia, agrotóxicos, mecanização intensiva e combate à fome. 


\section{temporalis}

Invisibilidade ou visibilidade negativa (criminalização) dos movimentos sociais de luta pela terra na cidade e no campo

1- Lutas sociais - especificidades dos movimentos sociais urbanos e rurais. Processo de urbanização e luta pela moradia;

2- Disputa por hegemonia e os distintos projetos de desenvolvimento agrário: assentados, camponeses e agronegócio etc.;

3- Os movimentos sociais ambientalistas e as formas de regulação do Estado. A proteção ambiental em defesa da vida humana e dos recursos naturais.

A atuação do Serviço Social em face das refrações da questão agrária, urbana e ambiental: possibilidades e limites

1- Gestão ambiental pública e privada e Serviço Social;

2- O Serviço Social e a educação ambiental crítica;

3- Formação profissional e questão urbana, agrária e ambiental;

4- Transformações estruturais no campo e na cidade e seus rebatimentos no Serviço Social sob três dimensões: da formação, do trabalho e da organização política dos Assistentes Sociais.

\section{ATIVIDADES REALIZADAS COM AVALIAÇÃO}

Em novembro de 2012, no Colóquio organizado no interior do XIII ENPESS, os professores apresentaram os resultados alcançados até o momento, a partir de um plano de trabalho no qual constavam:

- O levantamento das pesquisas e dos pesquisadores, para o desenho do estado da arte da produção de conhecimento na área temática;

- A organização de um número da Revista Temporalis, com artigos abrangendo vários aspectos dos debates em curso sobre o tema.

Com relação ao levantamento realizado, foram identificados vários grupos e núcleos, os quais vêm desenvolvendo pesquisas na área. São 21 programas e 63 grupos de pesquisa relacionados à área temática. É interessante observar que, em termos da produção que se conseguiu mapear, foi identificada uma liderança da região Nordeste nesse processo: 
Tabela 1 - Grupos e Núcleos de Pesquisa na área

\begin{tabular}{c|c}
\hline \multicolumn{2}{c}{ Grupos e Núcleos de Pesquisa na área } \\
\hline Região Norte & $3,2 \%$ \\
\hline Região Nordeste & $23,8 \%$ \\
\hline Região Centro-Oeste & $12,7 \%$ \\
\hline Região Sul I & $11,1 \%$ \\
\hline Região Sul II & $11,1 \%$ \\
\hline
\end{tabular}

Fonte: Dados apresentados no Colóquio do GTP, em novembro de 2012, pelas Profas. Maristela Dal Moro (UFRJ) e Maria das Graças e Silva (UFPE).

Nos encaminhamentos acordados após a apresentação, duas orientações foram destacadas, diante das dificuldades encontradas para a realização do mapeamento. UFAS presentes questionaram a metodologia, tendo em vista não terem sido contempladas no quadro apresentado. Assim, foi apontada a importância de se formalizar o levantamento dos programas e das linhas de pesquisa, que deverá se fortalecer com a contribuição das regionais da ABEPSS, somando-se com a possibilidade de realização de reuniões a partir do levantamento para a consolidação das informações.

Com relação à publicação de um número da Revista Temporalis, a proposta foi concretizada com o lançamento dessa revista, número 24, jul./dez. 2012, cujos artigos produzidos por autores e pesquisadores do GTP buscaram o diálogo com os eixos da área temática, citados anteriormente, socializando suas produções e reflexões no contexto da realidade brasileira.

Como síntese do debate e tendo em vista a importância da articulação das dimensões agrária, urbana e ambiental em uma perspectiva de totalidade, pontuando a ação do Estado, a relação com outros sujeitos políticos e o diálogo que a profissão estabelece com a temática, algumas ações mostraram-se necessárias para a continuidade dos trabalhos do GTP:

- Discutir o papel da atuação política do GTP;

- Consolidar a articulação entre CFESS/CRESS e ABEPSS na concretização do GTP;

- Sugerir a apresentação de uma mesa de debates no $14^{\circ} \mathrm{CBAS}$ (mesas simultâneas);

- Atualizar as informações do GTP no site da ABEPSS; 


\section{temporalis}

- Contribuir com a Política de Comunicação e Informação da ABEPSS;

- Atualizar a lista de e-mails e grupo virtual;

- Organizar encontros de área (entre um ENPESS e outro) ou estimular encontros regionais.

\section{PERSPECTIVA/PLANEJAMENTO/DESAFIOS}

Ainda que haja um avanço na identificação do estado da arte na área temática Questão Agrária, Urbana, Ambiental, dialogando com o Serviço Social, alguns desafios se apresentam, tendo em vista a tarefa de pensar a continuidade dos trabalhos do GTP e identificar as tendências das pesquisas na área temática.

Nesse sentido, alguns encaminhamentos estão sendo discutidos:

- Retomar a construção da ementa do GTP para enfatizar a perspectiva da totalidade nessa relação urbana, agrária e ambiental;

- Retomar o levantamento realizado até o presente momento, fazer ajustes e consolidar as informações, enfrentando alguns limites, como a incompletude e a inconsistência de informações já identificadas pela coordenação anterior;

- Mapear os grupos e núcleos de pesquisa (possibilidades de utilizar a ferramenta Fórum da ABEPSS para completar informações retiradas da CAPES e do (NPq);

- Retomar e atualizar a lista de participantes do GTP;

- Identificar a sinergia das pesquisas no período 2000/2012, tendo como fontes CBAS, ENPESS, Revista Temporalis e periódicos.

- Investir em espaços coletivos de reflexão e de apresentação das produções, contando com a participação do conjunto CFESSCRESS e com a presença de movimentos sociais, sujeitos políticos das lutas.

\section{CONSIDERAÇÕES PRELIMINARES}

O presente documento expressa o esforço de resgate sintético das produções e dos acúmulos produzidos pelo GTP desde a sua formação. Considerando ainda a recente criação das experiências dos GTPs por parte da ABEPSS como importante elemento 
dinamizador e condensador da produção de conhecimento para o Serviço Social, procuramos sistematizar nessas breves linhas elementos relacionados a premissas, ao que se construiu coletivamente até então no que tange à ementa e aos desafios postos à área desse momento em diante.

A centralidade, talvez, apoie-se nos desafios de maior articulação, como elemento fundamental para a consolidação do Grupo Temático de Pesquisa enquanto tal, e de enriquecimento do diálogo voltado à formação profissional e à articulação societária.

Não podemos desconsiderar, no entanto, as dificuldades objetivas, de caráter estrutural e conjuntural, para a garantia de uma articulação permanente e mais profícua na área. A intensificação do trabalho docente em contexto bastante adverso de precarização das condições de ensino, pesquisa e extensão, a dinâmica imposta por racionalidade produtivista, compromissada mais com a quantidade do que com qualidade, além da conjuntura de reposição intensa das atividades acadêmicas ao longo de 2013, após importante greve das universidades federais e estaduais de mais de 100 dias em 2012, impõem limites desafiadores para essa integração.

Com base no fomento da construção de canais de articulação e de diálogo entre as pesquisas e produções em curso, o universo temático demonstra sua relevância em face da complexificação dos antagonismos materializados nas manifestações de movimentos sociais em todo o mundo e particularmente no Brasil. Capitaneada historicamente por movimentos como o dos Sem Terra (MST) e os movimentos pelo direito à moradia e à reforma urbana, tais como a União de Moradia Popular, o Movimento Nacional de Luta pela Moradia e a Central de Movimentos Populares, entre outros, a reflexão sobre os dilemas na disputa pelo acesso à riqueza socialmente produzida com base na contraditória formação do agrário e do urbano no Brasil expressa-se na presença crescente do debate na agenda de sujeitos coletivos, os quais são importantes para a organização e o fortalecimento da categoria, como o conjunto CFESS-CRESS.

As linhas de pesquisa, as produções bibliográficas e a presença de mesas de debate em eventos de movimentos sociais, voltados para a formação política profissional, visando o reconhecimento da importância dessas lutas e dos movimentos sociais 


\section{tempordils}

como sujeitos centrais nas alianças para a construção de projeto ético de intervenção, justificam a demanda em torno dessa articulação proposta pelo GTP.

\section{REFERÊNCIAS}

ASSOCIAÇÃO BRASILEIRA DE ENSINO E PESQUISA EM SERVIÇO SOCIAL - ABEPSS. Ementa do GTP Questão Agrária, Urbana, Ambiental e Serviço Social. Temporalis, Brasília, ano 12, n.24, p. 461-466, jul./dez. 2012.

FOSTER, J. B. A ecologia de Marx: materialismo e natureza. Rio de Janeiro: Civilização Brasileira, 2011.

HARVEY, D. O direito à cidade. Lutas Sociais, São Paulo: NEILS Núcleo de Estudos de Ideologias e Lutas Sociais, n. 29, 2012.

IAMAMOTO, M. V. O Serviço Social na cena contemporânea. In: Serviço Social: direitos sociais e competências profissionais. Brasília: CFESS/ABEPSS, 2009. p. 15-50.

IAMAMOTO, M. V. Serviço Social em tempo de capital fetiche: capital financeiro, trabalho e questão social. 2. ed. São Paulo: Cortez, 2008.

IASI, M. L. As metamorfoses da consciência de classe: o PT entre a negação e o consentimento. São Paulo: Expressão Popular, 2006.

MARX, K. O Capital: crítica da economia política. 2. ed. São Paulo: Nova Cultural, 1985. (Os Economistas).

NETTO, J. P. Introdução ao método da teoria social. In: Serviço Social: direitos sociais e competências profissionais. Brasília: CFESS/ABEPSS, 2009. p. 667-700.

REVISTA TEMPORALIS. Brasília: ABEPSS, 2009.

WOOD, E. A separação entre o "econômico" e o "político" no capitalismo. In: . Democracia contra capitalismo. São Paulo: Boitempo, 2010. 